\title{
Three new species of the spider genus Pholcus (Araneae: Pholcidae) from Liaodong Mountain, China
}

\author{
Yanfeng Tong \& Lanzhu Ji
}

Tong, Y. \& Ji, L. 2010: Three new species of the spider genus Pholcus (Araneae: Pholcidae) from Liaodong Mountain, China. — Entomol. Fennica 21: 97-103.

Three new species of the genus Pholcus collected from Liaodong Mountain, China, are diagnosed, described and illustrated: Pholcus hamatus sp. n., Ph.jiuwei sp. n. and Ph. wangtian sp. n. With the three new species, the total number of Pholcus recorded in China is 58.

Y. Tong, Institute of Applied Ecology, Chinese Academy of Sciences, Shenyang, 110016, China, and Chemistry and Life Science College, Shenyang Normal University, Shenyang, 110034, China; E-mail:tyf68@hotmail.com

L. Ji, Institute of Applied Ecology, Chinese Academy of Sciences, Shenyang, 110016, China; E-mail: Ji.lanzhu@iae.ac.cn

Received 10 July 2009, accepted 24 November 2009

\section{Introduction}

Pholcus is the largest genus of the family Pholcidae and currently contains 159 valid species $(\mathrm{Hu}-$ ber 2009). It is very rich in species and widely distributed in the old world especially. They generally have a flat, plate-shaped cephalothorax with a black median line, without thoracic furrow, and an elongate or globose abdomen. The characters most useful in distinguishing Pholcus from other genera are the projections of the bulb, traditionally called the uncus, the appendix and the embolus (Huber 2001).

The spiders of Pholcus in China had not been revised for a long time, but recently they were revised by Zhang \& Zhu (2009). A total of 55 valid species of this genus have been recorded in China (Tong \& Li 2009, Zhang \& Zhu 2009).

Liaoning Province in the northeast of China and has a rich species diversity of the genus Pholcus. Eight Pholcus species have been recorded from this area previously: $P h$. clavimaculatus, Ph. crypticolens, Ph. fengcheng, Ph. gaoi,
Ph. guani, Ph. manueli, $P h$. phoenixus and Ph. suizhongicus (Song et al. 1999, Zhang \& Zhu 2009). After examining spider specimens collected from Liaodong Mountain, the east hilly area of this province, another three new Pholcus species were found and are described here.

\section{Material and methods}

Taxonomic descriptions and terminology follow Huber (2000). Photos were made with an Olympus E-410 zoom digital camera (10 megapixels) mounted on an Olympus SZX16 dissecting scope. Vulvae of females were cleared in lactic acid. All measurements given in the text are in millimeters. Leg measurements are shown as: total length (femur, patella, tibia, metatarsus, tarsus). Legs segments were measured on their dorsal side.

The following abbreviations are used in the text: $\mathrm{ALE}=$ anterior lateral eyes; $\mathrm{AME}=$ anterior median eyes; $\mathrm{PME}=$ posterior median eyes. 

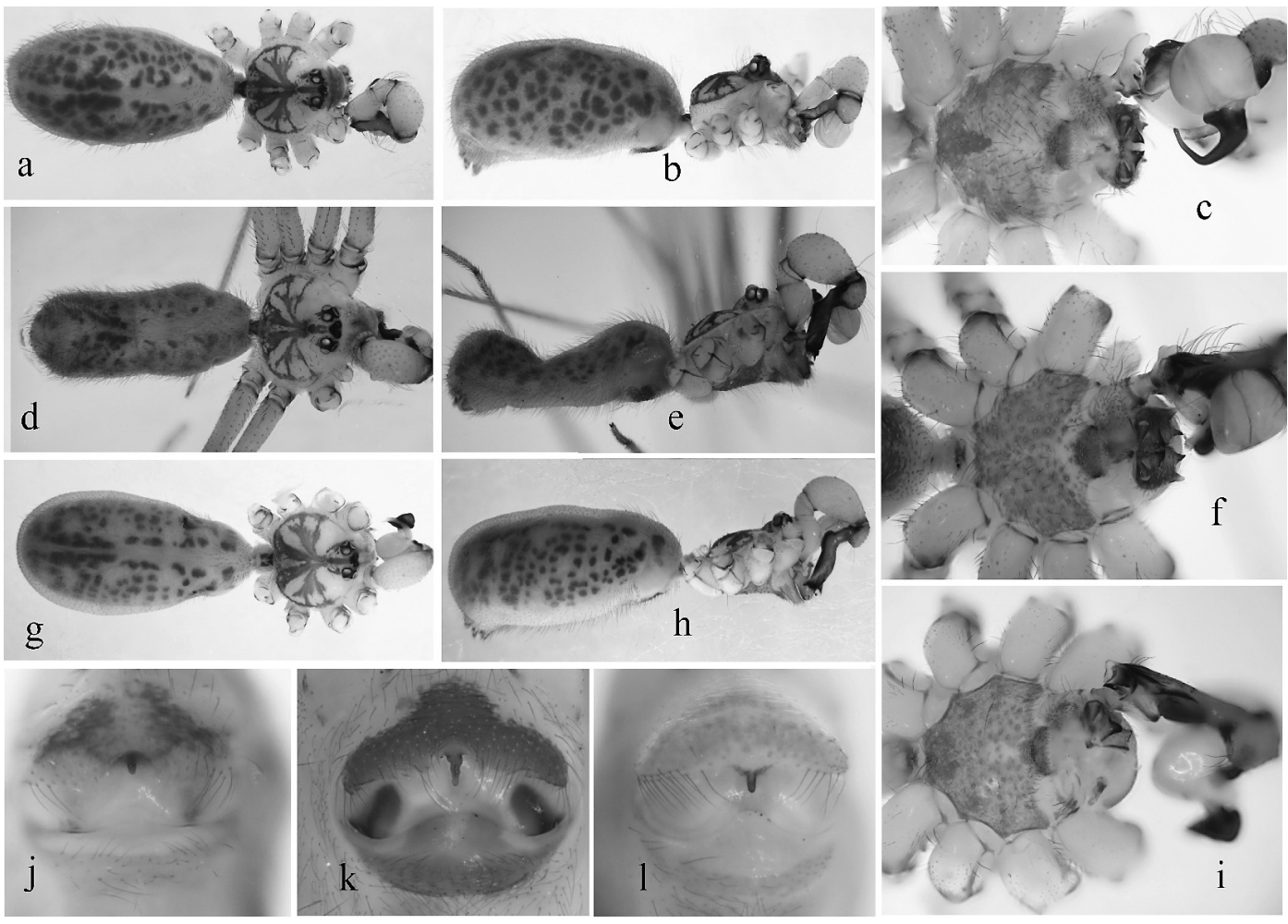

Fig. 1. Habitus, sternum and epigynum of three new Pholcus species: Ph. hamatus sp. n. (a-c, j), Ph. jiuwei sp. n. (d-f, k) and Ph. wangtian sp. n. (g-i, l). - a, d, g. Habitus, dorsal view. - b, e, h. Habitus, lateral view. $-\mathrm{c}, \mathrm{f}$, i. Sternum, ventral view. $-\mathrm{j}, \mathrm{k}$, l. Epigynum, ventral view.

\section{Description of new species}

Family Pholcidae C. L. Koch, 1850

Genus Pholcus Walckenaer, 1805

\subsection{Pholcus hamatus sp. n.}

Figs. 1a-c, j, 2, 5.

Type material. Holotype male, 9 males and 4 females paratypes, China, Liaoning Province, Benxi, Huanren Manchu Autonomous County, Wunüshan Hill (584 m a.s.1., $41^{\circ} 19^{\prime} \mathrm{N}$, $\left.125^{\circ} 25^{\prime} \mathrm{E}\right), 27$.VIII.2008, leg. Y. Tong.

Diagnosis. The new species is similar to Pholcus gaoi Song \& Ren, 1994, but can be distinguished by the shapes of uncus and procursus, the short spur of male palpal trochanter and the wing-like sclerotized arch of female vulva.

Description. Male (holotype): total body length 4.95 (5.26 with clypeus): cephalothorax 1.37 long, 1.58 wide; abdomen 3.58 long, 1.76 wide. Leg I: $38.02(10.14+0.71+10.03+15.43+$ 1.71), tibia II: 6.57 , tibia III: 4.57 , tibia IV: 6.86 ; tibia I L/D: 70. Habitus (Figs. 1a, b). Carapace short, broad and almost circular, ochre, with pair of brown marks broadly connecting to ocular area. Cephalic region raised, with brown stripe centrally, ocular area dark yellow. Clypeus dark ochre, without marks. Distance AME-AME 0.06; PME-PME 0.23. Diameter AME 0.11, ALE 0.15, PME 0.13, PLE 0.15. Chelicerae (Fig. 2d) with pair of black apophyses distally, pair of unsclerotized rounded apophyses proximolaterally and pair of black thumb-shaped apophyses proximocentrally. Labium and endites brown. Sternum yellow, with three pairs of marginal marks and one distinctive posterior mark (Fig. 1c). Legs brown, with dark rings on femora, patellae and tibiae; retrolateral trichobothrium of tibia 1 at $5 \%$. Abdomen cylindrical, pale ochre, dorsum with numerous brown patterns (Figs. 1a, b). Venter pale brown. Palps (Figs. 2a, b, c), bulb with long hook-shaped uncus, without appendix. 
Fig. 2. Pholcus hamatus sp. n. - a. Left palp, prolateral view. - b. Left palp, retrolateral view. - c. Distal part of left procursus, dorsal view. -d. Male left chelicera, frontal view. - e. Trochanter of male left palp, retrolaterodorsal view. $-\mathrm{f}$. Epigynum, ventral view. - g. Epigynum, dorsal view. Scale bars: $a, b, f, g=$ $0.3 \mathrm{~mm} ; \mathrm{c}, \mathrm{d}=0.2 \mathrm{~mm}$; $\mathrm{e}=0.1 \mathrm{~mm}$.
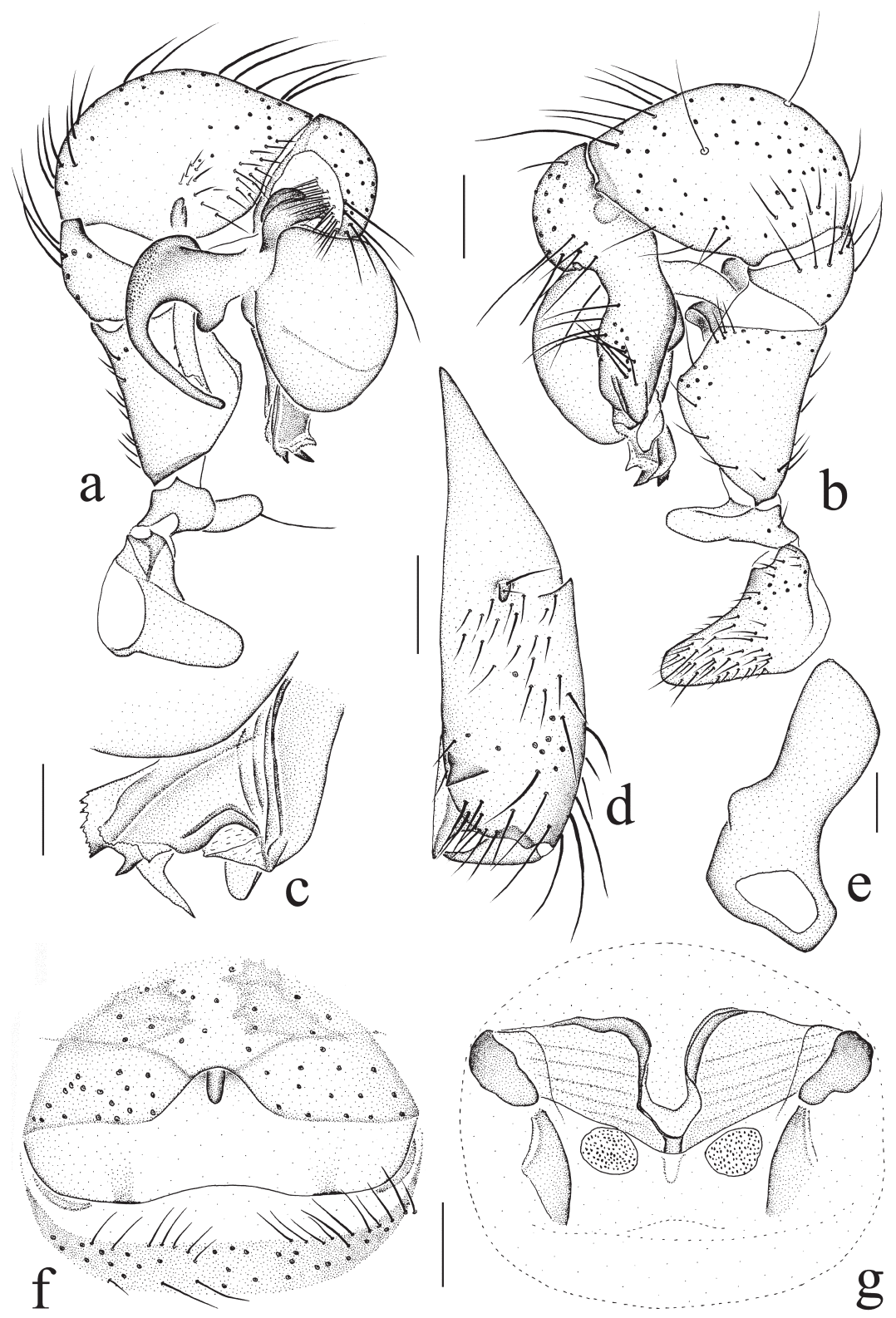

Tarsal organ capsulate.

Variation. Tibia I in other males $(n=9)$ : 8.42 10.53 (mean: 9.28).

Female. In general similar to male. Tibia $1(n$ =4): 5.79, 6.11, 6.74, 8.32. Epigynum (Figs. 1j, 2f), brownish with distinctive pattern; with short knob-shaped apophysis on top. Dorsal view (Fig. $2 \mathrm{~g}$ ), with wing-like sclerotized arch anteriorly and pair of oval pore plates.

Distribution. Known from the type locality only (Fig. 5).
Etymology. The species name is an adjective, referring to the long hook-shaped uncus on the male bulb.

\subsection{Pholcus jiuwei sp. n.}

Figs. 1d-f, k, 3, 5.

Type material. Male holotype, 2 males and 5 females paratypes, China, Liaoning Province, 


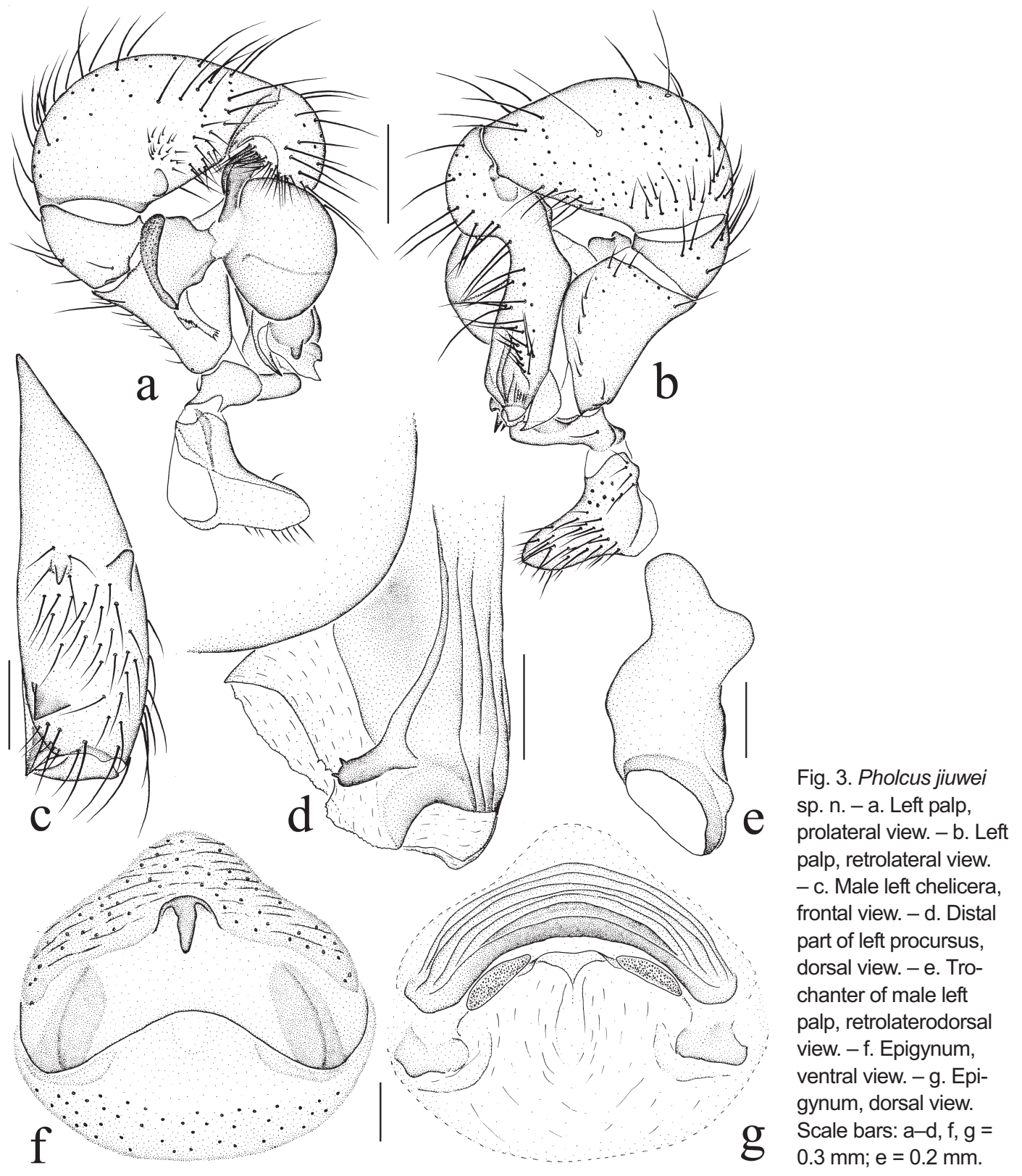

Benxi, Pingshan District, Xing'an Village

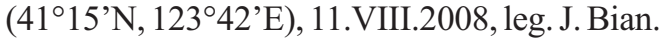

Diagnosis. The new species is similar to Pholcus joreongensis Seo, 2004, but can be distinguished by the shapes of the procursus and the spur of trochanter, the long knob-shaped apophysis on the top of epigynum and the long and narrow pore plates.

Description. Male (holotype): total body length 4.33 (4.67 with clypeus): cephalothorax
1.68 long, 1.7 wide; abdomen 4.21 long, 1.26 wide. Leg I: $40.56(10.53+0.74+10.63+16.83+$ 1.83), tibia II: 7.37, tibia III: 4.82, tibia IV: 6.74; tibia I L/D: 55. Habitus (Figs. 1d, e). Carapace short, broad and almost circular, ochre, with pair of brown marks broadly connecting to ocular area. Cephalic region raised, with brown stripe centrally, ocular area dark yellow. Clypeus dark ochre, without marks. Distance AME-AME 0.08; PME-PME 0.25. Diameter AME 0.11, 


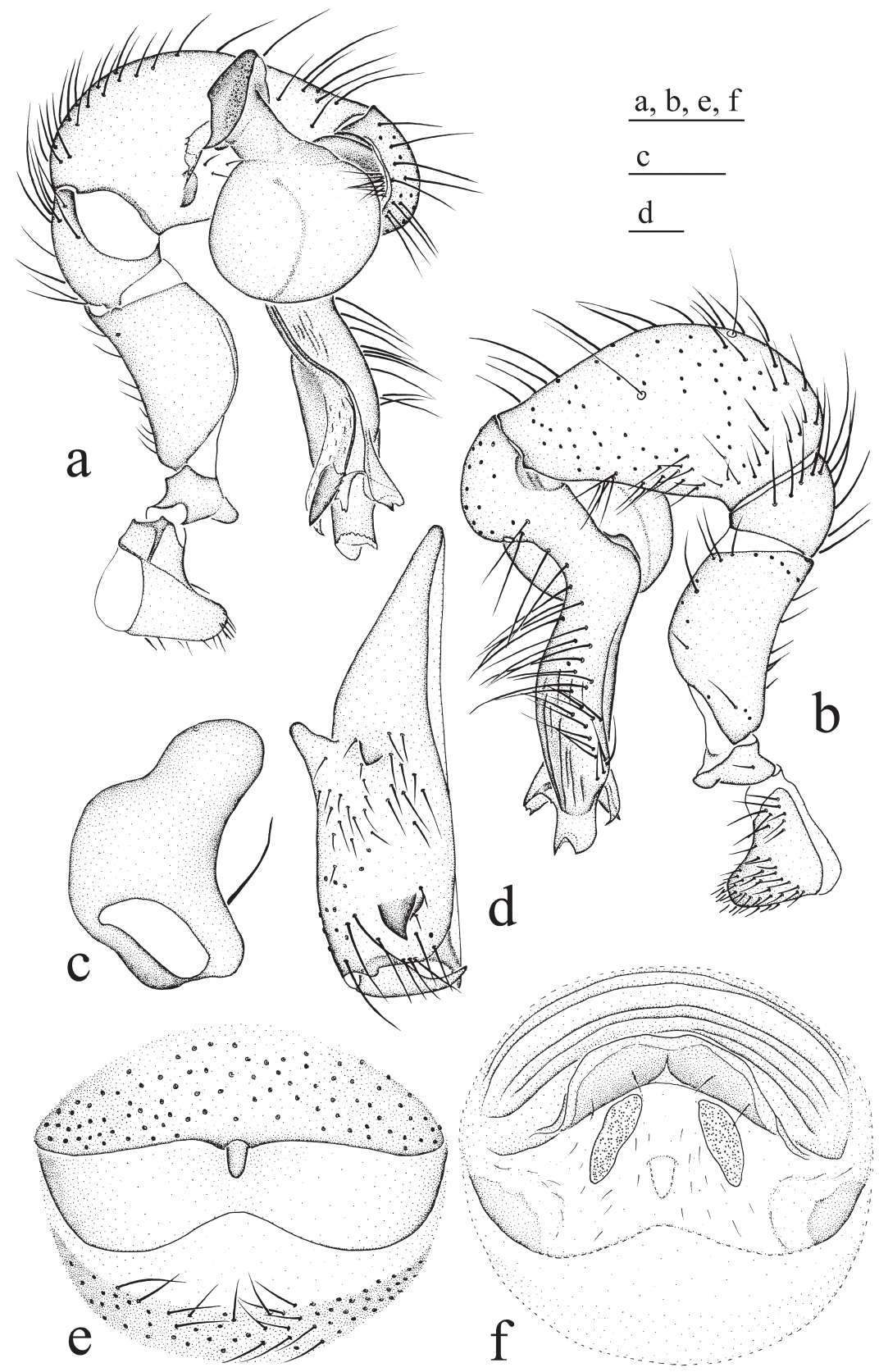

Fig. 4. Pholcus wangtian sp. n. - a. Left palp, prolateral view. - b. Left palp, retrolateral view. c. Trochanter of male left palp, retrolaterodorsal view. - d. Male right chelicera, frontal view. - e. Epigynum, ventral view. - f. Epigynum, dorsal view. Scale bars: $a, b, e, f=$ $0.5 \mathrm{~mm} ; \mathrm{c}, \mathrm{d}=0.2 \mathrm{~mm}$.

ALE 0.17, PME 0.14, PLE 0.15. Chelicerae as in Fig. 3c, with pair of black apophyses distally, pair of unsclerotized rounded apophyses proximolaterally and pair of black thumb-shaped apophyses proximocentrally. Labium and endites brown. Sternum yellow, with obscure marks along margin (Fig. 1f). Legs brown, with dark rings on femora, patellae and tibiae; retrolateral trichobothrium of tibia 1 at $6 \%$. Abdomen cylin- drical, pale ochre, dorsum with numerous brown patterns (Figs. 1d, e). Venter pale brown. Palps (Figs. 3a, b, d), bulb with square tile-shaped uncus, without appendix, procursus prolateraldistally with a short stick-shaped projection. Tarsal organ capsulate.

Variation. Tibia I in other males $(n=2$, one male leg I lost): 10.21 .

Female. In general similar to male. Tibia $1(n$ 


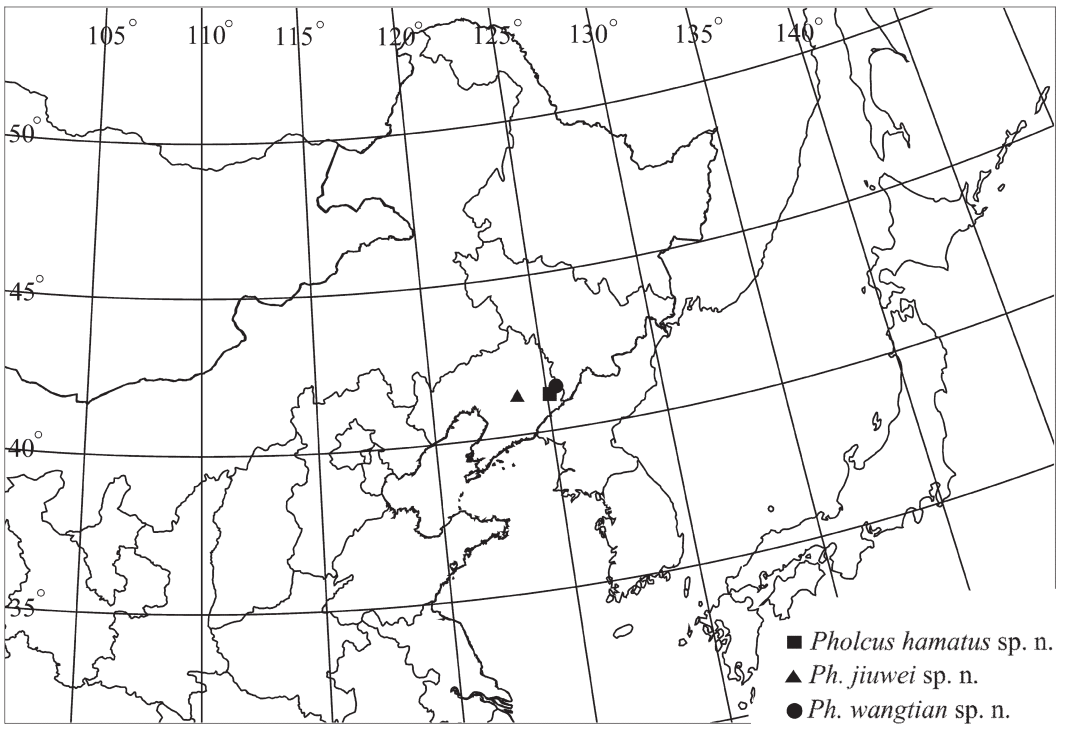

Fig. 5. Localities of three new Pholcus species from Liaodong Mountain, China.
= 5): 7.78-8.42 (mean: 8.09). Epigynum (Figs. $1 \mathrm{k}, 3 \mathrm{f}$ ), brown with distinctive pattern; with long knob-shaped apophysis on top. Dorsal view (Fig. $3 \mathrm{~g}$ ), with wavy sclerotized arch anteriorly and pair of long and narrow pore plates.

Distribution. Known from the type locality only (Fig. 5).

Etymology. Named for Mr. Jiuwei Bian, the collector of the type material.

\subsection{Pholcus wangtian sp. $\mathrm{n}$.}

Figs. 1g-i, 1, 4, 5.

Type material. Holotype male, 8 males and 18 females paratypes, China, Liaoning Province, Benxi, Huanren Manchu Autonomous County, Wangtian Cave $\left(41^{\circ} 11^{\prime} \mathrm{N}, 125^{\circ} 16^{\prime} \mathrm{E}\right), 26$.VIII. 2008, leg. Y. Tong.

Diagnosis. The new species is similar to Pholcus crassus Paik, 1978, but can be distinguished by the shapes of uncus and the procursus, the short male palpal trochanter spur and the long and narrow pore plates of female vulva.

Description. Male (holotype): total body length 6.42 (6.76 with clypeus): cephalothorax 1.68 long, 1.79 wide; abdomen 4.74 long, 2.32 wide. Leg I: $51.58(13.67+0.83+13.83+23.25+-)$, tibia II: 9.17, tibia III: 6.17, tibia IV: 8.33; tibia I L/D: 69. Habitus (Figs. 1g, h). Carapace short, broad and almost circular, ochre, with pair of brown marks broadly connecting to ocular area. Cephalic region raised, with brown stripe centrally, ocular area dark yellow. Clypeus dark ochre, without marks. Distance AME-AME 0.07; PME-PME 0.28. Diameter AME 0.11, ALE 0.18, PME 0.14, PLE 0.18. Chelicerae (Fig. 4d), with pair of black apophyses distally, pair of unsclerotized rounded apophyses proximolaterally and pair of small round apophyses proximocentrally. Labium and endites brown. Sternum yellow, with four pairs of brown marginal marks (Fig. 1i). Legs brown, with dark rings on femora, patellae and tibiae; retrolateral trichobothrium of tibia 1 at $6 \%$. Abdomen cylindrical, pale ochre, dorsum with numerous brown patterns as in Figs. 1g, h. Venter pale brown. Palps (Figs. 4a, b), bulb with bamboo-hat-shaped uncus, without appendix. Tarsal organ capsulate.

Variation. Tibia I in other males $(n=8)$ : 9.514.5 (mean: 12.21).

Female. In general similar to male. Tibia 1 ( $n$ =18): 8.75-10.5 (mean: 9.46). Epigynum (Figs. $11,4 \mathrm{e})$, yellow with distinctive pattern; with a short knob-shaped apophysis on the top. Dorsal view (Fig. 4f), with wavy sclerotized arch anteriorly and pair of narrow pore plates.

Distribution. Known from the type locality only (Fig. 5).

Etymology. The species name is a noun in apposition, derived from the type locality. 
Acknowledgements. We want to express our thanks to Dr. Barbara C. Baehr and Dr. Robert J. Raven (Queensland Museum, South Brisbane, Queensland 4101, Australia), who kindly checked the earlier draft of this manuscript and made many useful suggestions; to Dr. Byung-Woo Kim (National Park Research Institute, Namwon-si, Jeollabukdo, Korea) and Dr. Wonchoel Lee (Laboratory of Biodiversity, Department of Life Sciences, Hanyang University, Seoul, Korea) for providing us with valuable literatures and to an anonymous referee for comments on an early version of the manuscript. This study was supported by the China Postdoctoral Science Foundation (No. 2008043 1166) and by the Director Foundation of Experiment Center of Shenyang Normal University (SY200704).

\section{References}

Huber, B. A. 2000: New World pholcid spiders (Araneae: Pholcidae): A revision at generic level. - Bulletin of the American Museum of Natural History 254: 1-348.

Huber, B. A. 2001: The pholcids of Australia (Araneae; Pholcidae): taxonomy, biogeography, and relationships. - Bulletin of the American Museum of Natural History 260: 1-144.
Huber, B. A. 2009: Catalogue of Pholcidae. - [www document]. URL http://www.uni-bonn.de/ bhuber1/catalogue.htm. (Site visited on 15 October, 2009)

Paik, K. Y. 1978: The Pholcidae (Araneae) of Korea. Educational Journal of Kyungpook University 20: 113-135.

Seo, B. K. 2004: A new species of Pholcus (Araneae: Pholcidae) from Korea. - The Korean Journal of Systematic Zoology 20: 73-77.

Song, D. X. \& Ren, L. Y. 1994: Two new species of the genus Pholcus from China (Araneae: Pholcidae). Journal of Hebei Normal University (Natural Science Edition) (Suppl.): 19-23.

Song, D. X., Zhu, M. S. \& Chen, J. 1999: The Spiders of China. - Hebei Science and Technology Publishing House, Shijiazhuang. 640 pp.

Tong, Y. F. \& Li, S. Q. 2009: Six new cave-dwelling pholcid spiders (Araneae: Pholcidae) from Hainan Island, with two newly recorded genera from China. - Zootaxa 1988: 17-32.

Zhang, F. \& Zhu, M. S. 2009: A review of the genus Pholcus (Araneae: Pholcidae) from China. - Zootaxa 2037: 114 pp. 